\title{
Chapter 12 \\ University as State Agent or Social Actor: Al Akhawayn University and Social Responsibility
}

\author{
Mohammed Dahbi and Hassane Darhmaoui
}

\begin{abstract}
University Social Responsibility (USR) has been addressed in the academic literature and in professional educational meetings only in the last 10-15 years, but it is far from being unanimously accepted as part of a university's mission. A university is all about serving society anyway; its mission has always been to educate people, to train professionals, and to prepare young men and women for their roles as good citizens of their countries and of the world. So, what other social role is a university to serve that it does not? This issue becomes more acute and compelling when society's expectations of service from higher education institutions has to do with K-12 school education, as is the situation for the Covid-19 pandemic. The chapter considers the case of Al Akhawayn University (AUI) in Ifrane, Morocco (AUI), a university that has been established by the State as the first public, autonomous, non-governmental institution of higher education in the country. We describe several social roles that the university has taken on in its host region as well as nationally, most notably during the Covid-19 pandemic, and we argue that AUI has been able to do so because of its autonomy and its special legal status. We claim that non-autonomous state universities are not able to use the full potential of their sophisticated faculty and staff to contribute to the development of the country, and we call for the transformation of state universities into autonomous institutions that are able to serve their full Social Actor role and comply with their University Social Responsibility duties.
\end{abstract}

\subsection{Introduction}

Al Akhawayn University in Ifrane (AUI), Morocco, was inaugurated in January 1995 (www.aui.ma). In the poor, mountainous, rural area where the university campus is located, several student and faculty-led projects have aimed to alleviate

M. Dahbi $(\bowtie) \cdot$ H. Darhmaoui

Al Akhawayn University in Ifrane, Ifrane, Morocco

e-mail: M.Dahbi@aui.ma 
poverty and exclusion, especially in K-12 education. Many of these projects have benefited primary schools in the area, and some have even had a national impact, including the context of the current Covid-19 pandemic crisis. The chapter describes a few of the projects that have had an important impact and have continued to serve the needs of K-12 populations during the pandemic. The chapter addresses the following questions:

- Do these projects fit the role and purpose of a university?

- What objectives have these actions had, and what are the motives that moved faculty and students to act this way?

- Are these motives part of the declared mission of the university? Are they stated explicitly or are they part of unstated societal expectations?

In addition to these questions, the chapter will construct a coherent response that may be placed within a theoretical framework that considers a university's mission in a developing country like Morocco. Considering the varying statuses of higher education institutions in Morocco, from government universities to traditional and religious schools, and from non-profit institutions to private for-profit ones, one notices a clear change in the mission and outlook regarding the role of higher education in serving social needs. We propose to look at some of these outlooks as covering a continuum of social functions, ranging from a role as "State Agent" to a role as "Social Actor" depending on their affiliation with the government or their degree of institutional autonomy.

\subsection{Al Akhawayn University}

AUI's campus is in the Middle Atlas Mountains in the small town of Ifrane. It is surrounded by a thick forest with different varieties of oak and cedar trees. Economically, this mountainous area has benefited only from national tourism for its cool weather in the summertime and its snowfalls during the winter, which have been lighter and more irregular lately due to climate change. The rural communes in the area usually make a living from small to medium-size fruit tree agriculture, vegetables for local demand, sheep farming, and forestry. The lack of significant industrial and commercial activity has caused the area to suffer from poverty and economic stagnation. The decision to implant a national university with a large land endowment and a legal status that allows it to charge student tuition and fees has made a big difference in the region. AUI employs around 600 people, giving priority to hiring from the local workforce for small administrative, technical, and support needs. It has a student, faculty, and staff population of about 2500, representing different nationalities and coming from different parts of Morocco. As such, AUI is serving as a development engine contributing to empowering the economy of its host area while accomplishing its academic and scholarly mission.

The interest in K-12 education came naturally to AUI students and faculty because of the large contrast between a relatively rich and well-endowed institution, functioning with state-of-the-art levels of equipment and organization, on one hand, 
and the poorly endowed public-school institutions in the area, on the other hand. Several student-led initiatives by student associations like Hand in Hand, a solidarity association, and clubs such as Rotaract helped build public school classrooms, repaired and equipped others, bought fully supplied school bags for children, and developed a good knowledge base about primary education. An example of a faculty-led project is CITI (Center for Information Technology Innovation), later renamed CLT (Center for Learning Technologies), led by a physics professor ${ }^{1}$ who won a grant from the Korean International Cooperation Agency (KOICA) to develop distance education course materials for science subjects in public middle school. That was followed by a subcontract for national online teacher training course material supported by a USAID grant. Through these initiatives, the CLT and the university's distance education recording studio and post-production lab were developed and became available for the promotion of learning technologies in general and distance education projects. Other relevant projects include a student solidarity association building a rural school compound in the region, which includes a school, housing for staff, and a shop whose revenues serve to cover some of the basic needs of the school. A larger initiative led by a university president consisted of establishing a community development center in Azrou, the neighboring chief town with a much larger population and a much longer history in the area. The social contribution of the ACCD (Azrou Center for Community Development) will be covered in a separate section below.

AUI has had an affiliated K-12 school since day one; this is worth mentioning because it is an innovation in Morocco. ASI (Al Akhawayn School in Ifrane) has served and continues to serve the families of AUI faculty, staff, and other families in the region. It has also adopted an international model, closely related to the American school system in its organization and curriculum. It has no organic relations with the $\mathrm{K}-12$ education system in Morocco except that it must observe some basic curricular requirements. The school is funded by student tuition and heavily subsidized by AUI for the benefit of its own faculty and staff.

These initiatives are unique in the higher education landscape in Morocco. AUI was designed to be a different university that functions in accordance with the requirements of new models of international higher education: “... a new university, whose organizational, pedagogical and scientific structures are inspired by the most effective models, and which is meant to be a forum for the creation and confrontation of human progress in all fields of knowledge as well as a framework for cooperation and understanding among peoples and civilizations." autonomous institution that escapes the control of the government department in charge of education. It is endowed by the state from public resources, but it is not managed as a public administration. As such, it does not need to abide by rules and regulations specific to public schools. It hires and fires its own faculty and

\footnotetext{
${ }^{1}$ Prof. Hassane Darhmaoui, one of the two authors, continues to lead the Center for Learning Technologies.

${ }^{2}$ Quote from University Charter or Dahir. Last accessed at http://www.aui.ma/en/about/general/ history-mission.html
} 
administrative staff, and it is responsible for its own student outreach and recruiting. As a result, the university's mission and vision is in accordance with international standards, which has led it to pursue and gain international accreditation. ${ }^{3}$ The autonomy and freedom of management that AUI has enjoyed have enabled its students and faculty to be innovative in the various ways a Moroccan university can serve its social responsibility.

\subsection{University Social Responsibility (USR)}

What is the role of universities in the development of their host country? There is a consensus that a university's mission is the production and dissemination of knowledge, otherwise referred to as "teaching and research." Usually, the social service expected from universities is to educate citizens in the arts and sciences and to train the professionals that society needs. This is especially true of public universities funded largely by state budgets. In Morocco, the state provides for university education just as it provides for pre-school, primary, and secondary school education. This has led to tightly delineated administrative territories where public schools and universities are not necessarily expected to cooperate. Each institution must keep to its own mission and attempt to reach defined objectives within the many constraints that it must operate in. University academics are especially expected not to "interfere" with school education. Academics are reminded that they have not been trained or licensed as teachers, and that their job is very different from the job of schoolteachers. Often, higher education and school education have different government administrations. Even teacher training colleges, which are part of postsecondary education, have often been integrated into ministries in charge of school education to keep university academics away from school management. The mission of public universities and public schools is decided in the ministerial decrees that establish them, and their scope of operation is expressed in terms of age, grade level, or even geography. To achieve their mission, universities are allocated the material, human, and financial resources needed, and they are usually rather limited in the number of resources that they can get from outside government allocations.

Therefore, in this context, the debate about University Social Responsibility (USR) seems quite irrelevant. On one hand, the university has a social role, which is its academic mission. The rest of the needs of society are the responsibility of the state. The university serves society in its role as a State Agent in charge of higher education.

The view from the European Union Commission is quite different. The final report of the EU-USR Project (see https://www.eu-usr.eu (2015)) ${ }^{4}$ puts very strong

\footnotetext{
${ }^{3} \mathrm{AUI}$ is fully accredited by NECHE/NEASC, and its engineering and business schools both acquired international program accreditations (ABET and EPASS).

${ }^{4}$ EU-USR Project. (2015). University Social Responsibility: A Common European Reference Framework FINAL PUBLIC REPORT OF THE EU-USR PROJECT, 52709-LLP-2012-1-ROERASMUS-ESIN FEBRUARY 2015. Accessed at www.eu-usr.eu 12 August 2020.
} 
emphasis on the social dimension of higher education institutions. Although a European university's mission has always included the education of good citizens engaged for the good of their societies among its objectives (Zgaga, 2009 in www. eu-usr.eu), ${ }^{5}$ the additional objectives that are part of USR now include direct action to contribute to community development. Reporting on a survey of a large variety of European universities to find out how higher education institutions have been involved concretely, Nejati et al. (2011 in www.eu-usr.eu) $)^{6}$ says, "[o]ur thematic analysis reveals that 'community involvement and development' is the most frequent focus [...]." The second most frequent focus the survey found is "the environment," followed by "human rights" and "organizational governance."

AUI seems to be developing as a USR-oriented institution. Some of the initiatives we describe below, we argue, could not have been performed by state universities because of their design, their culture, and their administrative and financial structures. State universities act as State Agents who lack the autonomy and the social personality that would allow them to act differently. We will use the example initiatives presented below to describe some of the mechanisms that could work for AUI as a Social Actor and that were unavailable for state universities as State Agents.

\subsection{Digital Science Materials for Middle Schools}

The CITI (Center for Information Technology Innovation) project developed a platform that houses middle school science teaching materials available nationwide to students and teachers and continues to update the materials with mediated contributions from teachers. The platform with the digital materials has proved to be a very good resource for online education during the pandemic.

The CITI project objective was to foster ICT (Information and Communications Technology) expertise by bringing ICT into middle school classrooms in Morocco. The foundation of this work is a joint project between the Center for IT Innovation for Human Development laboratory at Al Akhawayn University in Ifrane, KOICA, the project "Generalization of New Information Technologies for Education" (GENIE) of the Moroccan Ministry of Education, and two pilot schools in Ifrane and Fez. The project agreement was signed in July 2006 and implemented from 2007 to 2009.

The specific choice of focus for this project was motivated by the very low level of exposure of Moroccan students and most instructors to IT tools in their secondary science education, the low performance of these students in scientific subjects in international rankings as compared to peers of the same educational level, the high dropout rate at the secondary and high school levels, and the national goal of

\footnotetext{
${ }^{5}$ Zgaga, P. (2009) Higher education and citizenship: 'the full range of purposes'. European Educational Research Journal, 8, 2, 175-188.

${ }^{6}$ Nejati, M., Shafaei, A., Salamzadeh, Y. \& Daraei, A. (2011) A study of top 10 world universities' websites. African Journal of Business Management, 5, 2, 440-447.
} 
increasing the number of graduates with IT skills to drive industrial development in certain key technological areas. This project has explored how IT-based education could improve both the motivation and performance of students in middle school.

Within the objectives of this project, CITI developed several math and science resources and tools for teachers and students in middle school. This development, which was carried out with the close participation of middle school teachers, was based on identifying and implementing best practices from IT-based education literature. The content design and development had a high degree of involvement from middle school teachers. ${ }^{7}$

The teams of teachers from the pilot schools, along with the pedagogical inspectors, have worked to develop content for courses using Microsoft Word and PowerPoint formats, conforming to the official educational programs for the 3 years of middle school. The content development task was divided among the teachers from the different pilot schools. The content defined by the teams is validated by the inspectors and AUI researchers and submitted to AUI software engineers and technicians. The task of the university area experts was to revise and convert the content to an adequate format, as well as to develop simulations corresponding to the different chapters. The developed material was returned to the teachers and then sent to the National Center for Innovative Pedagogy (CNIPE), who validated the developed materials.

The AUI team then placed the different materials developed online through a distance education platform (http://citi.aui.ma/). This website offers a variety of tools and applications that help students and teachers use ICT throughout the learning process. These include white board, class lectures, interactive exercises, online quizzes, simulations, video clips, virtual labs, educational podcasts, forums, and more. The implementation and experimentation phase in 10 pilot schools was followed by AUI researchers.

This experiment was the first of its kind in Morocco, and now our educational website (citi.aui.ma) is already listed on the platform of the Ministry of Education called TilmidTice (https://soutiensco.men.gov.ma/Home), which provides online support to students during the pandemic. CITI gives access to 853 digital resources that cover the science and mathematics subjects of the 7th, 8th, and 9th grades (Physics/Chemistry, Life and Earth Sciences, Mathematics). The content covers a total of 149 chapters, which is nearly the whole school program for mathematics and science in Grades 7-9. These resources are mainly PowerPoint presentations, simulations, video clips, course plans, online quizzes, and exams. Recently, a CD containing these resources was shared with public school colleagues to make it available to students who do not have Internet access, as well as to their instructors who have ideas on how to make use of the materials and how to develop further content. The link to the CD is: http://citi.aui.ma/Down/citi.aui.ma.zip (It requires

\footnotetext{
${ }^{7}$ See Omar Alj, 2014. Etude de l'intégration des TIC dans le Cadre du programme GENIE marocain : Attitudes des enseignants et impact dans les pratiques d'enseignement scientifique. Doctoral dissertation. Fes, Morocco: FSDM, Université Mohammed Ben Abdellah.
} 
Flash player). The link has also been shared for downloading the content on the CITI-association Facebook page: https://www.facebook.com/citi.association/.

What has enabled such an initiative? We can cite a few aspects dealing with the faculty member's status, the legal status of the institution, and the relationships between the university and the middle schools in the project. First, faculty members have the freedom of action and the incentive that allow them to apply for a grant and to negotiate such a project. Faculty are expected to be active in research and are evaluated and promoted on that basis. They are also allowed to have additional income from projects. Second, institutional donors such as KOICA or USAID are ready to fund such actions in the framework of the aid that they have planned for the country. However, they avoid dealing with public administrations since these administrations lack the administrative and financial autonomy to negotiate a contract and act as a fully responsible legal entity. A state university would have had difficulty observing the various requirements for the management of the cost center of the grant, including the accounting, the invoicing, the separate bank account, which is sometimes necessary, and all the different forms of auditing that a donor may require. Third, a state institution would have difficulty compensating the schoolteachers and other personnel involved in the project, and even when compensation is allowed, it is regulated by state rules and cannot be freely negotiated.

\subsection{A Center for Community Development}

The Azrou Center for Community Development serves as Al Akhawayn University's social arm in the region. ${ }^{8}$ In addition to adult literacy and other educational programs, a Non-Formal Education (NFE) program helps provide second chance education for school-age children who are uneducated or who have dropped out of the public school system. It is provided by Al Akhawayn University in partnership with the Ministry of Education and private donors such as the Pistorio Foundation, since 2009.

As the Ministry of Education in Morocco has announced the temporary suspension of schools starting from March 16, 2020 to reduce virus propagation, all schools decided to move to distance/online learning. Non-Formal Education programs at the Azrou Center were not an exception. Several measures were taken in the center to ensure that learning continues for all the students enrolled in the Non-Formal Education program.

Students and their trainers were all contacted about the program's necessary continuation via social media tools and through many distance learning options, such as the different platforms offered by the Ministry: https://soutiensco.men.gov.ma; https://telmidtice.men.gov.ma. Most of these sources make it possible to download

\footnotetext{
${ }^{8}$ The information provided to us by the Center Director Malika Iguenfer and the academic coordinator Mehdi El Idrissi is hereby acknowledged with much gratitude.
} 
material to be used offline. Students were also encouraged to follow educational programs broadcasted by the ministry on national TV channels.

WhatsApp groups corresponding to real instructor and student class groups were formed to facilitate the interchange between students and their teachers. WhatsApp groups were created for every subject, and they were monitored by the program supervisor. Accompanying classes of introduction to handiwork (sewing, embroidery, gardening, weaving) were interrupted, as access to the workshops by trainers was not allowed.

Use of Microsoft TEAMS was made possible by the ministry, but most of the students, coming from a disadvantaged background, do not have the required tools (such as computer and Internet connection) to use it. They preferred to use WhatsApp, as they are accustomed to using it for their daily communication. Teachers either send audio or video presentations and send materials with exercises for students to complete and send back. Others prepared videos, used Adobe software with the help of the center staff, and when necessary, they arranged a one-toone audio interchange with students.

The weekly schedule has been adjusted in a more flexible way for students to be connected each day with one teacher on one subject. To keep the programs going during these difficult times, the center continued to hold regular online meetings with the teachers to be informed on their new experience, to discuss the difficulties they meet, and to inform them of decisions taken by the provincial delegation of the Ministry of Education.

The center also tried to stay informed about any social problems that may hinder student learning, and as a result, decided to help first with paying for the mobile data fees for all the students who have access to a smartphone. All three national providers, as a rule, make it possible to purchase data online, so the center was able to provide limited online time for many students. It also provided food donations for families, especially during the concurrent holy month of Ramadan. Support for these actions came from individual donors and from a faculty, staff, and student fund-raising initiative by the university.

Teachers reported that teaching remotely has had, in general, a positive impact on most of the students, especially on those who used to spend most of their time in the streets to earn a living or beg for money and return home at night. Now, they stay mostly at home because many of the street markets and other commercial gatherings are closed. However, online teaching has been very challenging for students who could not afford to have the technological tools, nor have access to the Internet. $65 \%$ of the students, who have access to a smart phone, attended regularly, while the others were contacted by phone and advised to regularly watch the educational and literacy programs broadcast on national TV channels. As far as end-of-year exams are concerned, only continuous assessment grades that were assigned during the school year and until lockdown were counted.

Azrou Center for Community Development (ACCD) is another feature of AUI's autonomy. This is a center that was established with initial funding from private donors. The upkeep of the physical plant and the salaries of the permanent staff are supplied from the university's budget. Its operating budget and a modest capital 
budget are provided by the university, as well as by donations from the Ministry of National Education and by private donors, including the Italian Pistorio Foundation (www.pistoriofoundation.org). The entire national Non-Formal Education program is based on a public-private partnership, whereby NGOs would provide a home for the NFE classes, would recruit students mostly by door-to-door visits in specific neighborhoods, and would recruit volunteer teachers. The ministry would, in exchange, provide the NGO with an allocation calculated according to the number of registered students that the NGO declares. The salaries of the volunteer teachers are extremely modest, and they generally attract young university graduates who would like to become teachers and who seek to have some classroom experience before joining the public system when there are openings.

Because the NFE program does not partner with public institutions such as state universities, which are not known to have centers such as the ACCD, Al Akhawayn University has created an NGO called ADMA (Association de Développement du Moyen Atlas), which serves as the intermediary between public administration and AUI administration. Thus, AUI acts as a Social Actor deciding on a social initiative, making plans, and implementing them. Whereas the Moroccan government would not transfer funds to AUI for the ACCD activities, it approves of the Center and finds it extremely useful. ACCD is highly regarded, and it is used by the Ministry of Education as a reference center for Non-Formal Education due to its organization and serious pedagogy, as well as for the additional funds that the university and its private partners provide to make this school of a second chance more attractive and more successful.

\subsection{Crowdsourced Production of Children's Stories}

The Arabic Language Unit at AUI has initiated a crowdsourced competition to produce stories for children to promote reading and educational skills and values. A platform is being developed to provide stories for children that can be used for the purposes of reading and other language arts activities.

The group, which has been involved in this initiative, is the recently established Center for Arabic and Literacy Education (CALE), ${ }^{9}$ a faculty research and development group within the School of Humanities and Social Sciences (SHSS). The mission of CALE is to engage in research to support Al Akhawayn University's years-long efforts in the teaching of standard and dialectal Arabic for the benefit of its students, Moroccan and international, and for members of the AUI community. It also aims to promote scientific research on the Arabic language, literature, and culture, as well as to encourage artistic creation in this language. The center aims to bring together national and international scholars to share their expertise and scientific research to improve understanding of the Arabic language, literature, and

\footnotetext{
${ }^{9}$ Abdellah Chekayri, Professor of Arabic, is the initiator and leader of the project; his contribution to the presentation of the project is hereby acknowledged with gratitude.
} 
culture, and develop the most effective methodologies of Arabic literacy and language arts education in K-12 and university levels. It is set to provide an auspicious educational environment for millennials and other learners, designing and mobilizing state-of-the-art digital technologies to support learning and teaching for timesaving and quality Arabic literacy acquisition.

Leveled readers, classroom library corners, and illustrated stories are best practices in and out of schools and are considered excellent materials to help develop students' literacy. In Morocco, however, textbooks assigned by the Ministry of Education are the only materials usually available to public school students. School teachers closely follow these textbooks; as a result, children do not experience reading time for enjoyment, nor the freedom to read stories on their own without being constrained by teachers, curricula, and textbooks. The objective of this year's second edition crowdsourced contest in Arabic short story writing for children is to develop story reading resources that can be distributed and used by schoolchildren and their parents. This year's slogan is "achieving the sustainable development goals," and the overall objective is to develop children's reading skills by providing them with meaningful opportunities to engage with oral language and written texts. CALE aims to champion raising awareness about the 17 goals set by the United Nations Development Program (UNDP) so that Moroccan citizens can be acquainted with the challenges facing their future at an early age and to learn about Sustainable Development Goals (SDGs) through stories. The project also plans to involve university students in reading stories and discussing SDGs with early-grade children in schools in the Fez-Meknes region, an experience to be scaled up to other regions in Morocco. K-12 teachers would also benefit from an introduction to the best practices in language teaching and in promoting reading and writing within school communities.

This initiative is supported by a small seed grant from the Humanities and Social Sciences Dean and the university. It is in its second year, and it has already been able to attract the attention of national and international donors, but it needed the initial support from the university. A state university would not have been able to provide that support because there are no lines in its budget that would allow it to spend money on a similar project. Even if it did, the line would have to be quite large because of the many such research and development initiatives that its large and highly sophisticated faculty would require. This is another example of the freedom of action that an autonomous Social Actor university such as AUI enjoys. Providing for the development of reading skills in primary schools is the purview of another department, not for a state university who, as a State Agent, needs to spend its funds only on its tightly defined mission objectives. 


\subsection{PING Project: One Million Tablets - The Digital Leapfrog of the Moroccan Public Education System ${ }^{10}$}

The PING Project is an ambitious NGO-initiated project, supported by the Ministry of Education and hosted and implemented by Al Akhawayn University. The project, which is likely to last, offers a unique opportunity to leapfrog the digital transformation of the public education system in Morocco. This is what the Morocco PING Project has aimed to contribute through the deployment of 1,000,000 tablets to students at public schools across the country, starting with 10,000 tablets as a pilot phase. The tablets, loaded with available content, will serve as a virtual school during the pandemic and will help bridge the digital gap inside the classroom when normal schooling resumes.

The Covid-19 situation offers a unique opportunity to promote creative solutions that have been facing resistance in the past. Moving the education system to a digital era is a theme that has seen a tremendous amount of effort and funds deployed. There is, therefore, a wealth of information (content) and assets (platform, training, etc.) that exist and which, with the support of the Ministry of Education, this project will leverage upon. The tablets will be a virtual school while the pandemic is ongoing; it will then move to education portals and support for students to be used both in and outside of the classroom.

In the long run, the PING Project intends to promote a model that will need to be economically sustainable by ways yet to be identified, albeit supported by the Ministry of Education through direct and indirect subsidies. There are several avenues to achieve the business model sustainability, such as reinforcing the content platform and creating a "market" between content providers (e.g., course provider, tutoring, etc.), bandwidth providers (telecom operators), and end users (the student). A public-private partnership is proposed as part of the pilot and will be part of the evaluation process pre-PING launching.

Experience pleads for a strong involvement by all stakeholders. Children and their parents are pivotal to the success of the initiative. As such, it is paramount to envisage a contribution of the parents in the project, even if only symbolically. We have set said symbolic contribution to $10-40 \mathrm{MAD}^{11}$ per month (depending on the student's grade level). Similarly, we could envisage a contribution of other public stakeholders (e.g., the Assembly of the Region) to widen the stakeholder basis.

The leaders of this project are distinguished past public administration executives who knew that they could not partner with a state university for all the reasons mentioned above. They sought AUI as another Social Actor that has the autonomy to decide on joining such a project, negotiating its own role in it, and taking the liberty to support it at its pre-pilot stage.

\footnotetext{
${ }^{10}$ Younes Maamar is the leader of this project; we acknowledge with gratitude his contribution to the presentation of the project.

${ }^{11}$ The rate of exchange for the Moroccan Dirham (MAD) has been, on average for many years, 10 MAD to 1 USD.
} 


\subsection{Conclusion}

The above examples are some of the relevant initiatives that are currently active and that reflect the university's vision of its social responsibility. Beyond its academic and scholarly mission, AUI has been designed as a liberal educational system that promotes a model of the university graduate as a citizen of the world, aware of their responsibilities to actively engage in promoting change. All undergraduates need to satisfy the requirement of ca. $40 \%$ of credits in General Education, and no student can graduate without having satisfied the obligation of social service for a minimum of 60 hours. The Covid-19 pandemic has come as an unexpected test of how autonomous, reactive, and socially responsible a university can be. AUI immediately set up a Covid-19 Efforts Donation Fund subscribed to by faculty, staff, students, and the university budget. This has been useful to alleviate some poverty needs of the local population in the Ifrane Province. In addition, with uninterrupted synchronous online classes, continuing outreach, admissions and hiring activities, and with strategic planning and other administrative and financial activities going on, AUI will have passed the test of being a useful Social Actor. It continues to learn to be a socially responsible university which is developing a model to be emulated by private higher education institutions and later by state universities, having managed to become more autonomous.

Mohammed Dahbi's academic expertise is in language, linguistics, and literacy. He taught high school in England and in Morocco, and he spent a large part of his career teaching at Mohammed V University where he was also involved in teacher training and in many educational policy reform efforts. He participated as a consultant in the design of Al Akhawayn University and was appointed as the first dean of Humanities and Social Sciences. He also directed the Center for Academic Development and the Social Science Research Institute and served as the Chief Academic Officer (VPAA) of Al Akhawayn University. He directed several research projects in the areas of classroom discourse, conversation analysis, courtroom discourse, doctor-patient discourse, literacy acquisition, and language variation. He served as President and long-time member of the Moroccan American (Fulbright) Commission for Educational and Cultural Exchange, as member of the TOEFL Board, as member and chair of the TOEFL Grants \& Awards committee, as member of the King Abdulaziz Foundation for Humanities and Islamic Studies in Casablanca, and he continues to serve on the board of the American Cultural Association in Morocco. This long career has helped him develop expertise in research design, project management, and human resource management, and gave him access to an extensive professional network in Morocco and internationally. He holds an MA from the University of Southern California (1974) and a PhD from Georgetown University (1984).

Hassane Darhmaoui holds a PhD in Physics from the University of Alberta, in Canada. He joined Al Akhawayn University in Ifrane (AUI), Morocco, right after his graduation in 1997. He is currently an Associate Professor in the School of Science and Engineering and Coordinator of the AUI Center for Learning Technologies. His research in education focuses on ICT integration in science education, distance learning (eLearning, mLearning, MOOC), and Serious Games. He led to success several projects in the field; the latest were the ITQANE eLearning targeting teacher trainers, and the CITI-project about ICT integration in middle school science teaching. Dr. Darhmaoui's $R \& D$ research in physics and engineering mainly focuses on renewable energies applications. His current focus is on the development of simple energy-efficient systems easy to build and integrate 
in the local environment. Dr. Darhmaoui was a Fulbright scholar at the National Institute of Standards \& Technology, Boulder, Colorado, in the USA during summer 2002. He was also a visiting research scholar at the University of South Carolina, USA, during summer 2000. Dr. Darhmaoui is a co-author of more than 62 research papers and has more than 100 presentations in various conferences and scientific meetings. He is an active member in several scientific societies and groups.

Open Access This chapter is licensed under the terms of the Creative Commons Attribution 4.0 International License (http://creativecommons.org/licenses/by/4.0/), which permits use, sharing, adaptation, distribution and reproduction in any medium or format, as long as you give appropriate credit to the original author(s) and the source, provide a link to the Creative Commons license and indicate if changes were made.

The images or other third party material in this chapter are included in the chapter's Creative Commons license, unless indicated otherwise in a credit line to the material. If material is not included in the chapter's Creative Commons license and your intended use is not permitted by statutory regulation or exceeds the permitted use, you will need to obtain permission directly from the copyright holder. 